http://jmscr.igmpublication.org/home/ ISSN (e)-2347-176x ISSN (p) 2455-0450

crossref DOI: https://dx.doi.org/10.18535/jmscr/v8i3.69

\author{
Dournal Of Medical Science And Clinical Research \\ IGM Publication \\ An official Publication of IGM Publication
}

\title{
Pattern of dermatological disorders among patients attending OPD at a Government hospital in North India
}

\author{
Authors \\ Dr Waleed Karra ${ }^{1}$, Dr Zoya Ayesha ${ }^{2 *}$ \\ ${ }^{1}$ Master's in Dermatology, Junior Resident, Government Medical College, Anantnag, J\&K. \\ ${ }^{2}$ Senior Resident, in Department of Pathology, Sheri Kashmir Institute of Medical Sciences, Srinagar, J\&K \\ *Corresponding Author \\ Dr Zoya Ayesha \\ Department of Pathology, Sheri Kashmir Institute of Medical Sciences, Jammu and Kashmir, India
}

\begin{abstract}
Background: Skin diseases are most common health problems worldwide and it continues so because of difference in the availability of health care access, type of health care and most important awareness of the common man to the importance of early diagnosis and treatment of skin diseases.

Methodology: A hospital based cross sectional study was conducted in Government Medical College Anantnag. All the patients attending the OPD for 1 month were included in the study. A total of 1515 patients were seen and thus included in the study.

Results: In our study, the majority of patients were in the age group of 21-30 years (37\%), females (54.3\%), belonged to joint families $(70.1 \%)$ and majority were married (75.1\%). The majority of the patients had non-infectious form of skin disease (60.9\%) and less had infectious form of skin diseases. Among the non-infectious form of skin disorders, the common one was eczema. The most common form of infectious skin disorder was scabies.

Conclusion: Overall the burden of skin diseases is high in the population. There is a need for imparting awareness regarding the prevent ability and early detection of skin diseases.

Keywords: Dermatology, Scabies, eczema, tinea infection.
\end{abstract}

\section{Introduction}

Dermatology is the branch of medicine that deals with diagnosis and treatment of skin, hair and nail related disorders. It is a vast growing branch as large number of skin related pathological conditions are emerging these days. ${ }^{(1)}$ Skin is also the largest and most visible organ of the body which acts as the first barrier against injury and bacterial infestation therefore reflecting the health status of the body. Skin changes are affected with aging due to passage of time and photo-aging due to exposure to the sun, with signs of xerosis, fine wrinkling, thinning of skin, loss of elasticity, seborrhoeic keratosis, coarse deep wrinkling, skin tag, etc. ${ }^{(2)}$ The pattern of skin diseases varies from region to region due to difference in ecological, social and genetic factors and hygienic standards. ${ }^{(3)}$. In developing countries, poor hygiene, lack of basic amenities, and overcrowding also play significant role in occurrence of few skin diseases. In addition, profile of skin disorder among patient is 
influenced by the distance needed to travel to seek health care. ${ }^{(4)}$.

Regarding skin disorders, males are more commonly afflicted with infectious diseases whereas women are more vulnerable to psychosomatic disorders, autoimmune, pigmentary as well as allergic diseases. ${ }^{(5)}$. There is a high prevalence of dermatological disorders with significant morbidity in patients admitted in hospitals as well ${ }^{(6)}$. Dermatological problems constitute at least $30 \%$ of all outpatient visits to a pediatrician and $30 \%$ of all visits to a dermatologist involve children. The prevalence of these disorders among children in various parts of India ranges from $8.7 \%$ to $35 \%$. $^{(7)}$

There are various diseases and syndromes well documented with a cutaneous marker. Certain dermatological diseases such as psoriasis are associated with metabolic syndrome and cardiovascular disease. There is an increased prevalence of various cutaneous infections with diabetes mellitus and other immune-compromised states. $^{(8)}$

\section{Aim and Objectives}

The study was done to assess the pattern of dermatological disorders among patients attending OPD at a Government Medical College Anantnag.

\section{Methodology}

The study was cross sectional study conducted at Government Medical College Anantnag, J \& K. All the patients presenting with dermatological complaints in OPD were enrolled in the study. The study was conducted during a time period of 1 month during which a total of 1515 were included in the study. Participants were interviewed using a structured questionnaire. Information was obtained regarding demographic and socio-economic characteristics. The collected data was entered in Microsoft Excel. Data was described in terms of percentages.

\section{Results}

The study was conducted during a period of 1 month with a total of 1515 participants. The majority of the patients who were included belonged to the age group of 21-30 years (37.0\%), were females $(54.3 \%)$, , belonged to a joint family (70.4\%), and were married (75.1\%). [Table 1].

Table 1: Socio - demographic characteristics of participants

\begin{tabular}{|c|c|c|}
\hline Characteristic & Number $(n=1515)$ & Percentage (\%) \\
\hline \multicolumn{3}{|l|}{ Age (years) } \\
\hline $11-20$ & 289 & 19.0 \\
\hline $21-30$ & 562 & 37.0 \\
\hline $31-40$ & 228 & 15.0 \\
\hline $41-50$ & 198 & 13.0 \\
\hline $51-60$ & 162 & 11.0 \\
\hline$>60$ & 76 & 5.0 \\
\hline \multicolumn{3}{|l|}{ Gender } \\
\hline Male & 692 & 45.7 \\
\hline Female & 823 & 54.3 \\
\hline \multicolumn{3}{|l|}{ Family type } \\
\hline Nuclear & 448 & 29.6 \\
\hline Joint & 1067 & 70.4 \\
\hline \multicolumn{3}{|c|}{ Marriage status } \\
\hline Unmarried & 377 & 24.9 \\
\hline Married & 1138 & 75.1 \\
\hline
\end{tabular}

The non-infectious form of skin diseases was more common as compared to infectious disorders. (Table 2)

Table 2: Distribution of skin disorders:

\begin{tabular}{|l|c|c|c|}
\hline Diagnosis & \multicolumn{2}{|c|}{ Gender } & Total \\
\hline Non-infectious & Male & Female & \\
\hline Infectious & 367 & 557 & 924 \\
\hline
\end{tabular}

The distribution of non - infectious form of skin disorders is given as under :(Table 3 )

Table 3: The distribution of non-infectious skin disorders is as under

\begin{tabular}{|l|c|c|c|c|}
\hline Diagnosis & \multicolumn{3}{|c|}{ Number (n=924) } & $\begin{array}{c}\text { Percentage } \\
(\%)\end{array}$ \\
\hline & Male & Female & Total & Total \\
\hline Eczema & 74 & 92 & 166 & 17.9 \\
\hline Vitiligo & 55 & 43 & 98 & 10.6 \\
\hline Melasma & 25 & 64 & 89 & 9.8 \\
\hline Psoriasis & 72 & 80 & 152 & 16.4 \\
\hline Acne Vulgaris & 64 & 95 & 159 & 17.2 \\
\hline Urticaria & 22 & 64 & 86 & 9.3 \\
\hline $\begin{array}{l}\text { Drug } \\
\text { Eruptions }\end{array}$ & 40 & 45 & 85 & 9.2 \\
\hline Miscellaneous & 43 & 46 & 89 & 9.6 \\
\hline
\end{tabular}


The distribution of infectious form of skin disorders is under (Table 4)

Table 4: Distribution of infectious form of skin disorders is as under:

\begin{tabular}{|l|c|c|c|c|}
\hline Diagnosis & \multicolumn{3}{|c|}{ Number (n=591) } & $\begin{array}{c}\text { Percentage } \\
(\%)\end{array}$ \\
\hline & Male & Female & Total & Total \\
\hline Scabies & 63 & 93 & 156 & 26.5 \\
\hline Tinea Infection & 62 & 59 & 121 & 20.5 \\
\hline $\begin{array}{l}\text { Pityriasis } \\
\text { Versicolor }\end{array}$ & 54 & 63 & 117 & 19.8 \\
\hline Candidiasis & 42 & 51 & 93 & 15.6 \\
\hline Herpes Zoster & 16 & 22 & 38 & 6.4 \\
\hline Chicken pox & 10 & 11 & 21 & 3.6 \\
\hline Warts & 30 & 15 & 45 & 7.6 \\
\hline
\end{tabular}

\section{Discussion}

The rise of skin related problems are high specially in our country. This can be attributed to hot- humid climatic condition, low socioeconomic status, religions, lack of access to primary health care, poor educational status. The pattern of skin disorders varies from country to country but also within the same country in different parts. So, frequency of different skin disorders in different parts of the same country should be studied. ${ }^{(1)}$

In our study, the majority of the patients belonged to the age group of 21- 30 years with a percentage of $37.0 \%$, followed by the age group of $11-20$ years, followed by age group of 31-40 years and then the least participants belonged to the age group of $>60$ years.

The majority of the patients were females $(54.3 \%)$ as compared to the males (45.7\%). The majority of the patients belonged to joint families $(70.4 \% 0$ as compared to nuclear families $(29.6 \%)$. The majority of the patients were married $(75.1 \%)$ followed by unmarried (24.9\%).

The most common form of skin disorder was noninfectious as compared to the infectious form of disorders.

In the non-infectious form of skin disorders, the most common form was eczema (17.9\%), followed by acne vulgaris (17.2\%), followed by psoriasis (16.4\%), followed by vitiligo (10.6\%), followed by melasma (9.8\%), followed by miscwllanous group (9.6\%), followed by urticarial (9.3\%) and the last being drug eruptions $(9.2 \%)$. The non -infectious form of skin disorders were more common among females as compared to males.

In the infectious form of diseases, the most common was scabies (26.5\%), followed by tinea infections (20.5\%), followed by pityriasis versicolor $(19.85 \%)$, followed by candidiasis $(15.6 \%)$, followed by warts $(7.6 \%)$, followed by herpes zoster $(6.4 \%)$ and the least found were cases of chicken pox(3.6\%).

\section{Conclusion}

The frequency of skin disorders is increasing day by day. The pattern of skin diseases varies from one country to another country and in various regions within the same country. The emerging challenges for dermatologists are to prevent and reduce these skin diseases that pose a major healthcare burden, as well as affecting the quality of patients' lives. There should be training programmes for diagnosing and managing common skin disorders for general practitioners and primary health care physicians to reduce referrals to tertiary care hospitals. ${ }^{(2)}$ The most predominant patients attended the skin OPD belongs to low socioeconomic status which comprise of basically farmers, construction workers and others from rural areas. ${ }^{(1)}$ Improvement education, personnel hygiene, the standard of living, environmental sanitation, and good nutritious food may help us to bring down the skin diseases in this area. Hence the aim of this study was to enforce the necessity of education, good health care system, environmental sanitation, good nutrition and maintenance of personnel hygiene as a whole can bring down the percentage of skin related diseases and improvement in the quality of life, hence more studies in this field is required which can give deeper insight on the pattern and their extent of effect on the quality of life. ${ }^{(1)}$

\section{References}

1. Sharma H, Chawla RK, Pruthi S. The 
pattern of dermatological disorders among patients attending OPD of dermatology department At a Tertiary Care Hospital , Mathura. IP Indian J Clin Exp Dermatology. 2019;5(2):154-7.

2. Rao MKP, Vd MD, Prasad PG, Derm MD. A Study Of Pattern Of Various Skin Diseases In Patients Attending To SKIN OPD, RIMS General Hospital , Srikakulam , Andhrapradesh. IOSR J Dent Med Sci. 2018;17(9):38-45.

3. Aman S, Nadeem M, Mahmood K, Ghafoor MB. Pattern of skin diseases among patients attending a tertiary care hospital in Lahore, Pakistan. J Taibah Univ Med Sci [Internet]. 2017;12(5):3926. Available from: http://dx.doi.org/10.1016/j.jtumed.2017.04 .007

4. Dimri D, B VR, Singh AK. Profile of Skin Disorders in Unreached Hilly Areas of North India. Hindawi Publ Corp. 2016;2016.

5. Sharma S, Vyas K, Trivedi DP, Vyas R. Demographic Distribution of Various Skin Diseases in Patients Visiting Tertiary Care Hospital in Saurashtra region, Gujarat , India. Int $\mathbf{J}$ Contemp Med Res. 2016;3(6):1742-6.

6. Aleem S, Sameem F, Manzoor S. Dermatology Inpatient Consultations: A One Year Experience from a Tertiary Care Centre in Northern India. Int J Contemp Med Res. 2018;5(3):3-6.
7. Reddy VS, Anoop T, Ajayakumar S, Bindurani S, Rajiv S, Bifi J. Study of clinical spectrum of pediatric dermatoses in patients attending a Tertiary Care Center in North Kerala. Indian $\mathbf{J}$ Paediatr Dermatology. 2016;17(4).

8. Williams A, Bhatia A, Kanish B, Chaudhary PR, Samuel CJ. Pattern of Inpatient Dermatology Consultations in a Tertiary Care Centre from Northern India. J Clin Diagnostic Res. 2016;10(12). 